\title{
Article \\ Identification of DNA Damage Repair-Associated Prognostic Biomarkers for Prostate Cancer Using Transcriptomic Data Analysis
}

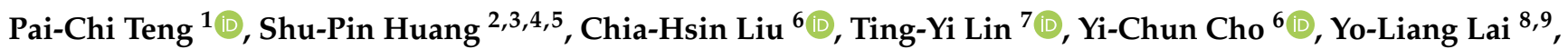 \\ Shu-Chi Wang ${ }^{10}{ }^{D}$, Hsin-Chih Yeh ${ }^{2,11} \mathbb{D}$, Chih-Pin Chuu ${ }^{12}$, Deng-Neng Chen ${ }^{13}$, Wei-Chung Cheng ${ }^{6,8,14, *}$ \\ and Chia-Yang $\mathrm{Li}^{15, * \mathbb{D}}$
}

\section{check for} updates

Citation: Teng, P.-C.; Huang, S.-P.; Liu, C.-H.; Lin, T.-Y.; Cho, Y.-C.; Lai, Y.-L.; Wang, S.-C.; Yeh, H.-C.; Chuu, C.-P.; Chen, D.-N.; et al. Identification of DNA Damage Repair-Associated Prognostic Biomarkers for Prostate Cancer Using Transcriptomic Data Analysis. Int. J. Mol. Sci. 2021, 22, 11771. https://doi.org/10.3390/ ijms222111771

Academic Editor: Peter J.K. Kuppen

Received: 24 September 2021

Accepted: 29 October 2021

Published: 29 October 2021

Publisher's Note: MDPI stays neutral with regard to jurisdictional claims in published maps and institutional affiliations.

Copyright: (C) 2021 by the authors Licensee MDPI, Basel, Switzerland. This article is an open access article distributed under the terms and conditions of the Creative Commons Attribution (CC BY) license (https:// creativecommons.org/licenses/by/ $4.0 /)$.
1 Taipei City Hospital Renai Branch, Taipei 10629, Taiwan; paichi.teng@gmail.com

2 Department of Urology, School of Medicine, College of Medicine, Kaohsiung Medical University, Kaohsiung 80708, Taiwan; shpihu73@gmail.com (S.-P.H.); patrick1201.tw@yahoo.com.tw (H.-C.Y.)

3 Department of Urology, Kaohsiung Medical University Hospital, Kaohsiung Medical University, Kaohsiung 80708, Taiwan

4 Graduate Institute of Clinical Medicine, College of Medicine, Kaohsiung Medical University, Kaohsiung 80708, Taiwan

5 Ph.D. Program in Environmental and Occupational Medicine, College of Medicine, Kaohsiung Medical University, Kaohsiung 80708, Taiwan

6 Research Center for Cancer Biology, China Medical University, Taichung 40403, Taiwan; b881642@gmail.com (C.-H.L.); demicho.0111@gmail.com (Y.-C.C.)

7 Department of Medical Research, Taipei Veterans General Hospital, Taipei 11217, Taiwan; lintingyi2014@gmail.com

8 Graduate Institute of Biomedical Science, China Medical University, Taichung 40403, Taiwan; yolianglai@gmail.com

9 Department of Radiation Oncology, China Medical University Hospital, Taichung 40403, Taiwan

10 Department of Medical Laboratory Science and Biotechnology, Kaohsiung Medical University, Kaohsiung 80708, Taiwan; shuchiwang@kmu.edu.tw

11 Department of Urology, Kaohsiung Municipal Ta-Tung Hospital, Kaohsiung 80145, Taiwan

12 Institute of Cellular and System Medicine, National Health Research Institutes, Miaoli 35053, Taiwan; cpchuu@nhri.edu.tw

13 Department Management Information Systems, National Pingtung University of Science and Technology, Pingtung 91201, Taiwan; dnchen@mail.npust.edu.tw

14 Ph.D. Program for Cancer Biology and Drug Discovery, China Medical University and Academia Sinica, Taichung 40403, Taiwan

15 Graduate Institute of Medicine, College of Medicine, Kaohsiung Medical University, Kaohsiung 80708, Taiwan

* Correspondence: wccheng@mail.cmu.edu.tw (W.-C.C.); chiayangli@kmu.edu.tw (C.-Y.L.)

Abstract: In the recent decade, the importance of DNA damage repair (DDR) and its clinical application have been firmly recognized in prostate cancer (PC). For example, olaparib was just approved in May 2020 to treat metastatic castration-resistant PC with homologous recombination repair-mutated genes; however, not all patients can benefit from olaparib, and the treatment response depends on patient-specific mutations. This highlights the need to understand the detailed DDR biology further and develop DDR-based biomarkers. In this study, we establish a four-gene panel of which the expression is significantly associated with overall survival (OS) and progression-free survival (PFS) in PC patients from the TCGA-PRAD database. This panel includes DNTT, EXO1, NEIL3, and EME2 genes. Patients with higher expression of the four identified genes have significantly worse OS and PFS. This significance also exists in a multivariate Cox regression model adjusting for age, PSA, TNM stages, and Gleason scores. Moreover, the expression of the four-gene panel is highly correlated with aggressiveness based on well-known PAM50 and PCS subtyping classifiers. Using publicly available databases, we successfully validate the four-gene panel as having the potential to serve as a prognostic and predictive biomarker for PC specifically based on DDR biology. 
Keywords: prostate cancer (PC); DNA damage repair (DDR); DDR-based transcriptomic biomarker; prognostic marker; cancer survival

\section{Introduction}

Prostate cancer (PC) is the second most commonly diagnosed cancer in men with an estimate of 1.4 million new cases, causing approximate 374,000 deaths worldwide in 2020 [1]. Androgen deprivation therapy has been the mainstay of systemic treatment for PC; however, many patients eventually develop metastasis and resistance to androgen deprivation therapy, and the transition to metastatic castration-resistant PC (mCRPC) represents a lethal evolution of PC. In the recent decade, the advent of next-generation hormonal therapies such as abiraterone [2], enzalutamide [3], apalutamide [4], and darolutamide [5] has significantly impacted the treatment paradigm and survival of PC patients. Other treatment options for advanced PC include taxanes, antibody-drug conjugates, radium-223, DNA damage repair (DDR) inhibitors, etc [6]. Of note, olaparib, a poly (adenosine diphosphate [ADP]-ribose) polymerase (PARP) inhibitor, was approved in 2020 as the first targeted therapy against a specific molecular phenotype of mCRPC with certain DDR gene mutations $[7,8]$.

Many studies have reported both somatic and germline mutations of DDR pathways in PC. For example, The Cancer Genome Atlas (TCGA) dataset revealed the inactivation of DDR genes including BRCA1, BRCA2, CDK12, ATM, FANCD2, and RAD51C in $19 \%$ of tissues collected from 333 localized PC patients who underwent radical prostatectomy [9]. A systemic review by Lang et al. summarized 11,648 records from 80 studies and demonstrated that the median prevalence rates for somatic and germline mutations of DDR genes were $10.7 \%$ and $18.6 \%$, respectively [10]. Among these, BRCA2, ATM, and PALB2 genes had higher mutation rates of $\geq 4 \%$ [10], while in mCRPC, $19.3 \%$ of aberrations in $B R C A 2, B R C A 1$, and $A T M$ genes were found in bone or soft tissue tumor biopsies that were substantially more frequently compared to those in primary PC tissues [11].

Certain DDR genes such as BRCA1, BRCA2, and ATM encode proteins that are essential for repairing DNA double-strand breaks by homologous recombination repair (HRR) $[12,13]$. The mutations involved in these genes can lead to carcinogenesis. DNA single-strand breaks are repaired by PARP enzymes (i.e., "nicks" in the DNA). PARP inhibitors can trap PARP enzymes at sites of DNA nicks and inactivate the repair of singlestrand breaks that ultimately progress to double-strand breaks [14]. It was observed that $P A R P 1^{-/-}$mice did not develop early-onset malignancy, but BRCA2-deficient cells were sensitive to PARP inhibitors [15], so the rationale and application of adding PARP inhibitors such as olaparib to cause death of tumor cells especially with defective HRR capacity has been developed in treatment for cancers including PC [16].

The results of the PROfound trial $[7,8]$, which categorized the enrolled patients into cohort $\mathrm{A}$ who had at least one mutation in $B R C A 1, B R C A 2$, or ATM genes and cohort $\mathrm{B}$ who had at least one mutation in any of the other 12 genes, led to the FDA approval of olaparib use in mCRPC with one of the 15 mutated HRR genes including BRCA1, BRCA2, $A T M$, etc. Interestingly, a clinical benefit with statistical significance was not observed in the patients of cohort B receiving olaparib, while the patients of cohort A had significantly longer median progression-free survival (PFS) and overall survival (OS) with olaparib administration [7]. This observation highlights the need to delineate the genomic indicators and further understand the detailed biology of DDR specifically for PC.

In addition to HRR, there are at least five other major DDR pathways such as base excision repair, nucleotide excision repair, mismatch repair, non-homologous end-joining, and Fanconi anemia DNA repair pathways [17-19]. In this study, we aimed to identify genes that are significantly associated with these DDR pathways and examine their contributions to survival in PC using our previously developed user-friendly platform, i.e., DriverDBv3 [20]. It was found that the expression of a four-gene panel including DNTT, EXO1, NEIL3, and EME2 was the most significantly associated with OS of PC patients 
through a rigorous bioinformatic process; moreover, gene expressions were examined based on two well-established PC classifiers, i.e., PAM50 [21] and PCS [22,23], and it was found that the expression of the four-gene panel was significantly correlated with aggressiveness based on PAM50 and PCS subtypes, both of which have been validated for their clinical significance including prognostication and prediction of treatment response in PC $[24,25]$. These findings demonstrate the potential application of a DDR pathway-based transcriptomic panel as a prognostic and predictive biomarker in PC.

\section{Results}

2.1. Identification of DDR Genes Associated with Overall Survival in Prostate Cancer

Firstly, genes related to six major DDR pathways in the Kyoto Encyclopedia of Genes and Genomes (KEGG) pathway database [26,27] were examined including base excision repair, nucleotide excision repair, mismatch repair, HRR, non-homologous end-joining repair, and Fanconi anemia DNA repair pathways (Figure 1). A total of 154 genes involved in DDR pathways in the KEGG database were identified and transcriptomic profiling of 153 genes with associated clinical data exported from TCGA-PRAD [9] through our previously developed DriverDBv3 platform [20] (Supplementary Table S1). One of the 154 genes, GTF2H2C_2, did not have expression data and was therefore excluded. The individual expression of the 153 DDR-associated genes was examined in PC and benign prostate tissue. Significantly differentially expressed (SDE) genes were selected if their absolute value of $\log _{2}$ fold change was greater than 1 (i.e., $\left|\log _{2} \mathrm{FC}\right|>1$ ) with $p$ value of less than 0.05. Consequently, eight SDE genes were identified, including RAD51, RPA4, $S L X 1 B, P O L N, E M E 2, E X O 1, D N T T$, and NEIL3. The corresponding survival data of the eight SDE genes including hazard ratio (HR) of OS and $\mathrm{p}$ value are shown in Table 1.

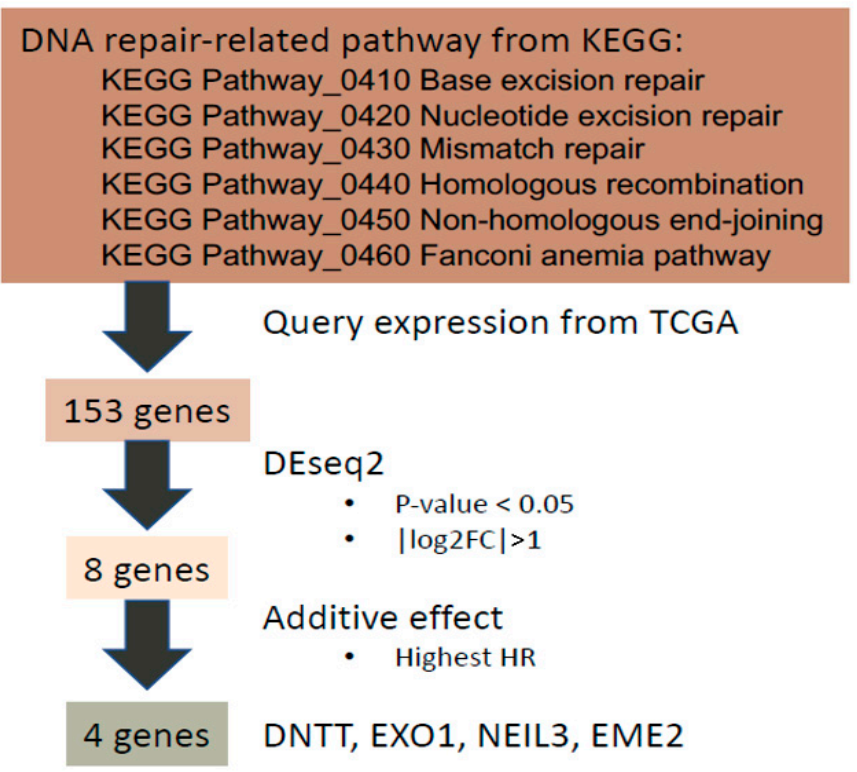

Figure 1. The workflow of developing our 4-gene panel as a transcriptomic biomarker for PC prognosis.

The functional annotation of the eight SDE genes was investigated using the KEGG pathway [27] (Figure 2a) and Reactome pathway databases [28] (Figure 2b). The KEGG analysis showed three common repair pathways enriched by a six-gene network, from genes required for inducing double-strand break formation (EME2), DNA intercross linkstrand unhooking (SLX1B) to excision of mispaired DNA (EXO1), guiding homologous recombination (RAD51, RPA4) to DNA resynthesis (POLN). The pathway enrichment showed that five genes were present in the Fanconi anemia pathway, a generalized pathway encompassing sequential steps critical in DNA repair. 
Table 1. The $\log _{2}$ fold change and corresponding hazard ratio (HR) of overall survival (OS) for each significantly differentially expressed (SDE) gene.

\begin{tabular}{|c|c|c|c|c|}
\hline SDE Gene & $\log _{2}$ Fold Change & Adjusted $p$ Value of SDE & HR of OS & $p$ Value of OS \\
\hline RAD51 & 1.02 & $5.92 \times 10^{-11}$ & 1.88 & 0.36 \\
\hline RPA4 & 1.18 & $1.83 \times 10^{-6}$ & 2.15 & 0.26 \\
\hline SLX1B & 1.02 & $2.2 \times 10^{-3}$ & 1.25 & 0.73 \\
\hline POLN & 1.00 & $7.16 \times 10^{-19}$ & 1.99 & 0.30 \\
\hline$E M E 2$ & 1.29 & $1.16 \times 10^{-18}$ & 5.67 & 0.07 \\
\hline EXO1 & 1.27 & $2.82 \times 10^{-11}$ & 1.75 & 0.51 \\
\hline DNTT & -1.20 & $1.1 \times 10^{-2}$ & 1.22 & 0.85 \\
\hline NEIL3 & 1.93 & $1.21 \times 10^{-18}$ & 2.01 & 0.31 \\
\hline
\end{tabular}

(a) Functional annotation of 8 DE genes: KEGG

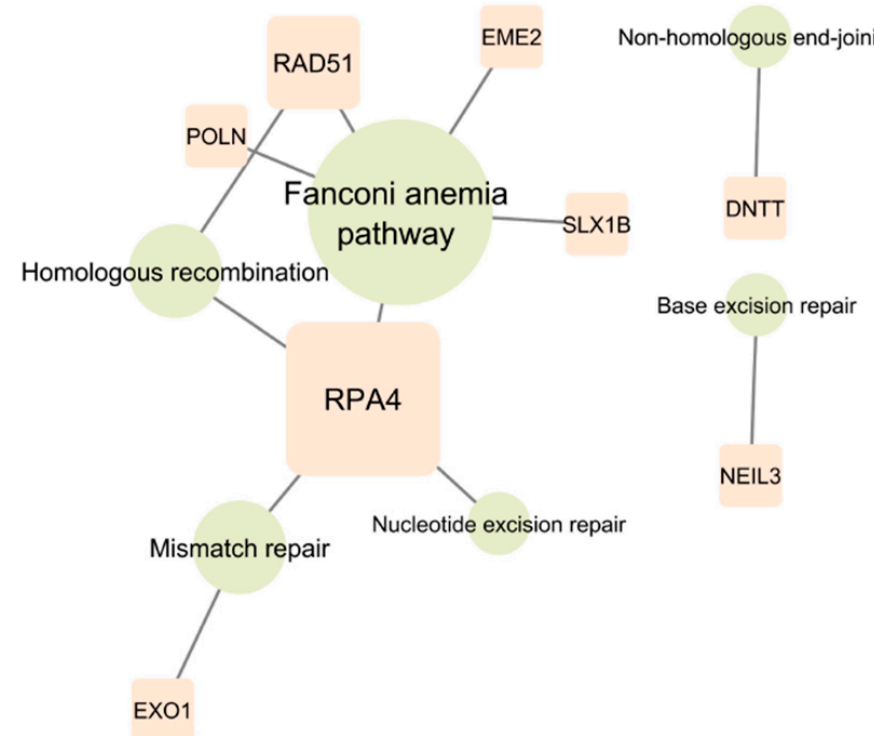

(b) Functional annotation of 8 DE genes: Reactome

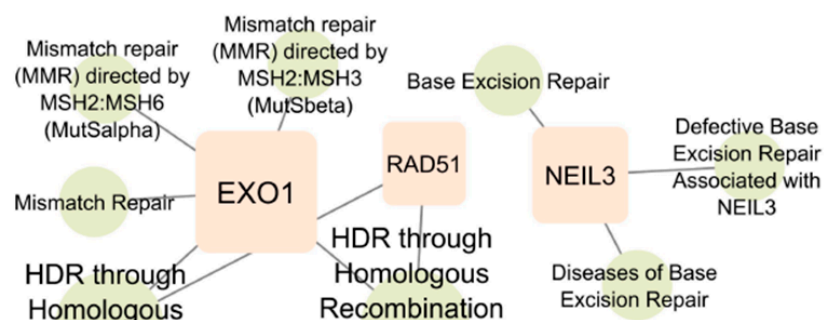

$\begin{array}{cc}\text { Recombination } & \text { (HRR) or Single } \\ \text { (HRR) } & \text { Strand }\end{array}$ Excision Repair

Figure 2. (a) Functional annotation of 8 SDE genes based on the KEGG database. (b) Functional annotation of 8 SDE genes based on the Reactome database.

Enriched pathways in mismatch repair, homologous recombination and Fanconi anemia serve as critical genomic stability/integrity regulators. The other analysis in Reactome further identified the enriched genes as being involved in deregulations of initial steps in mismatch repair by the $M S H 2 / 6$ and 2/3 complex. Consistent with the KEGG analysis, the Reactome analysis also identified a second DNA repair pathway from mismatch repair. NEIL3 enriched pathways involved in base excision repair differ from mismatch repair in purpose, method, and enzymes involved. Contrary to mismatch repair that corrects misincorporation during synthesis, base excision repair restores oxidative bases from oxidative reactions and basic sites that result from ionizing radiation, heat, and spontaneous base loss. However, the DNTT gene is not annotated in the Reactome database. All the other signaling pathways involving the eight SDE genes are illustrated in Supplementary Figure S1.

\subsection{Identification of a Four-Gene Panel as Prognostic Markers for PC Survival}

The HR of the eight SDE genes in PC survival analysis was examined using TCGAPRAD database. There were 497 patients who had OS and transcriptomic data of the eight SDE genes listed in Table 1. To obtain an optimal panel of genes that had the greatest 
contribution to prognostication, the additive effect of any combination of the eight SDE genes on HR of OS was investigated. As the expression of DNTT gene is downregulated in PC compared to benign prostate tissue (Table 1), the $\log _{2}$ expression of DNTT gene was multiplied by minus one for the analysis of additive effect. As the median $\mathrm{Z}$ score of each gene combination was set as the cutoff, the patients were grouped into higher or lower expression groups. As shown in Figure 3, higher Z scores of DNTT, EXO1, NEIL3, and EME2 genes resulted in the highest HR of OS among all the 255 combinations, while Kaplan-Meier analysis demonstrated that the patients with higher expression of the four-gene panel (i.e., DNTT, EXO1, NEIL3, and EME2) were significantly associated with poorer OS compared to the patients with lower expression (log-rank $\mathrm{HR}=13.1,95 \%$ confidence interval $(\mathrm{CI})=1.59$ to $108.03, p=0.0028$, Figure $4 \mathrm{a})$. The patients with higher expression of the four-gene panel also had significantly worse PFS compared to those with lower expression (log-rank HR $=3.44,95 \% \mathrm{CI}=2.16$ to $5.49, p<0.0001$, Figure $4 \mathrm{~b}$ ). The Kaplan-Meier plot of individual genes is illustrated in Supplementary Figure S2.

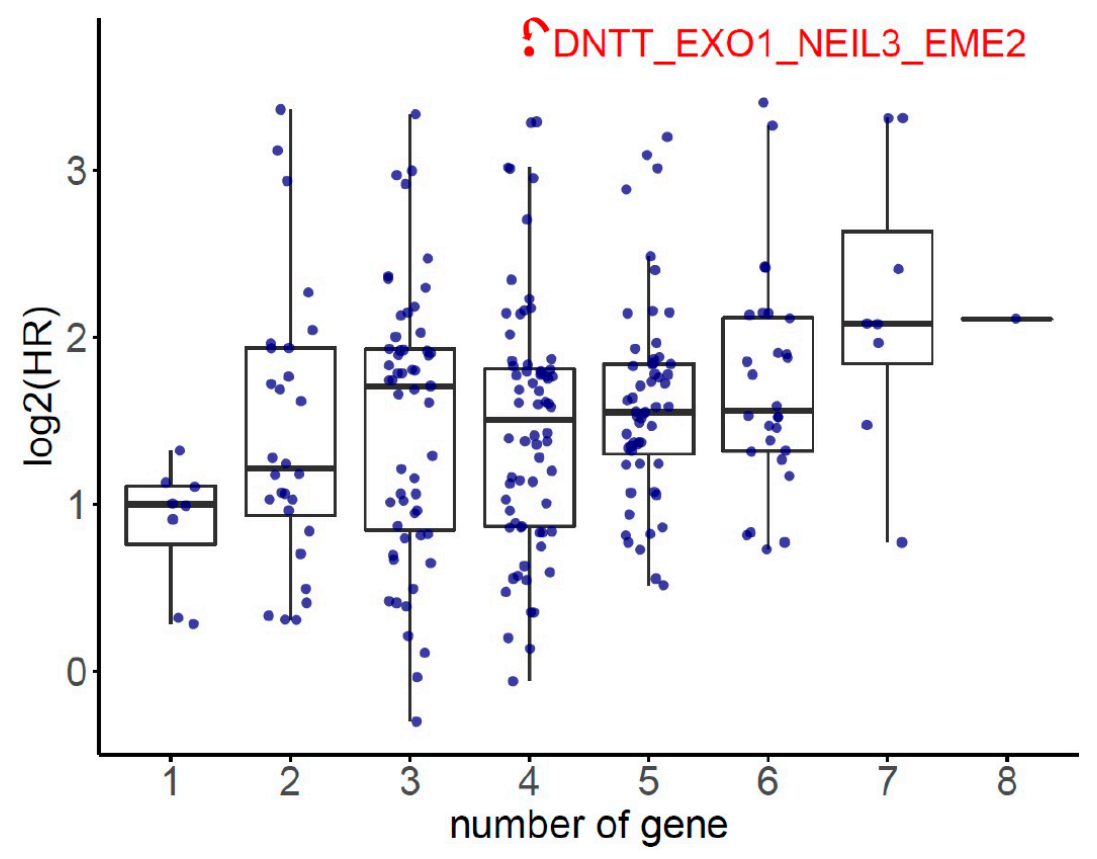

Figure 3. The additive effect on hazard ratio (HR) of overall survival (OS) for each combination of any of the 8 SDE genes.

\subsection{Multivariate Cox Regression Analysis}

A multivariate Cox regression model [29] was conducted to adjust possible clinical confounding variables including age (years), baseline prostate-specific antigen (PSA) levels (ng/mL), TNM stages (T1N0M0 or T2N0M0 vs. others), and Gleason scores ( $\leq 7 \mathrm{vs.}>7$ ). Notably, there were only three M1 (i.e., PC with distant metastasis) patients in this study because all the PC tissues were obtained from primary PC by radical prostatectomy. As shown in Table 2, the patients with higher four-gene expression were independently associated with poorer OS (Cox HR $=13.8,95 \% \mathrm{CI}=1.21$ to $158, p=0.0348$ ) and PFS (Cox HR = 2.32, $95 \% \mathrm{CI}=1.36$ to $3.95, p=0.0020)$. The patients with Gleason scores $>7$ had significantly worse PFS compared to those with Gleason scores $\leq 7$ (Cox HR $=2.71,95 \% \mathrm{CI}=1.61$ to 4.56 , $p=0.0002)$. Otherwise, the remaining clinical variables did not reach statistical significance in this multivariate Cox regression model. 
(a) Overall survival (OS)

Log-Rank $P$ value $=2.78 \times 10^{-3}$ Hazard Ratio $=13.1$ num. of high $=248$ num. of low $=249$

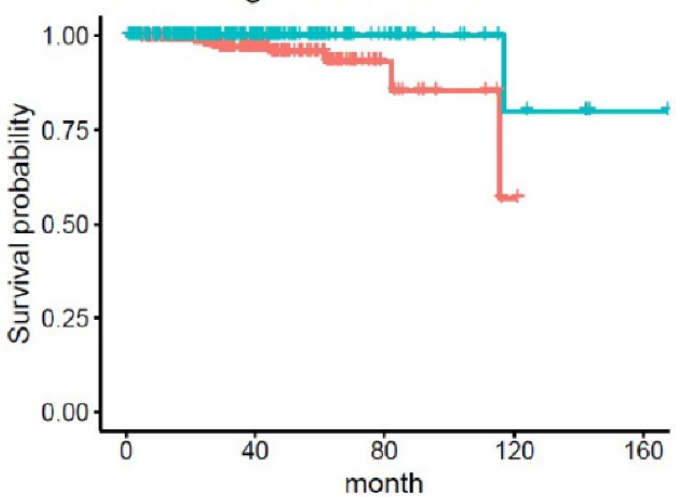

Number at risk

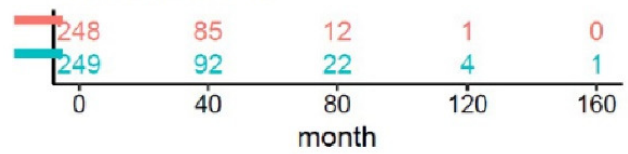

(b) Progression-free survival (PFS)

Log-Rank $P$ value $=3.33 \times 10^{-8}$ Hazard Ratio $=3.44$ num. of high $=248$ num. of low $=249$

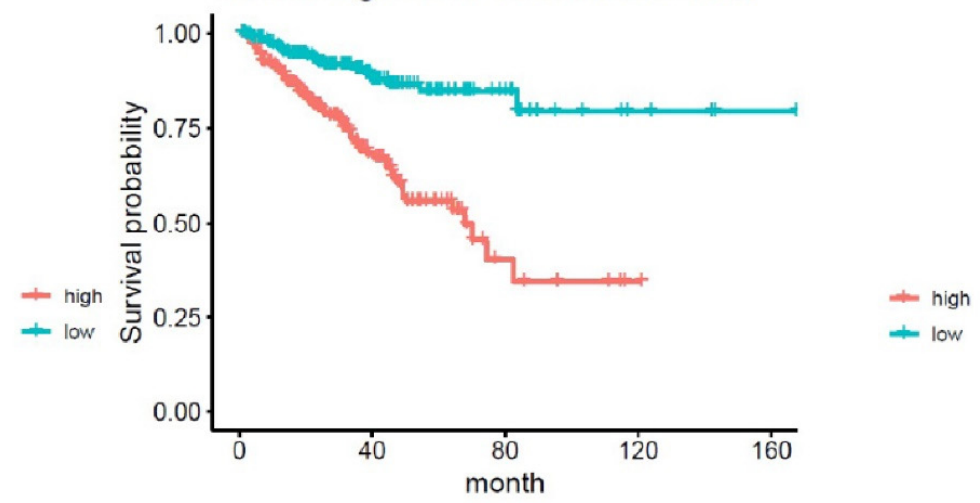

Number at risk

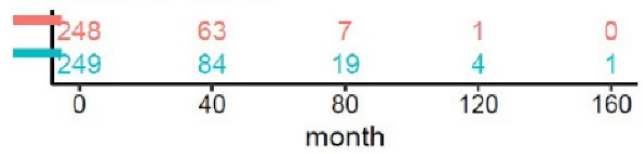

Figure 4. Kaplan-Meier analysis of (a) overall survival and (b) progression-free survival (PFS) in patients with higher vs. lower expression of the 4-gene panel (DNTT, EXO1, NEIL3, and EME2).

Table 2. Multivariate Cox regression analysis for OS and PFS.

\begin{tabular}{|c|c|c|c|c|}
\hline Variables for OS & HR & Lower $95 \%$ CI & Higher $95 \% \mathrm{CI}$ & $p$ Value \\
\hline \multicolumn{5}{|l|}{ 4-gene expression } \\
\hline Lower & ref & ref & ref & ref \\
\hline Higher & 13.8 & 1.21 & 158 & 0.0348 \\
\hline Age (year) & 1.05 & 0.95 & 1.15 & 0.3667 \\
\hline PSA (ng/mL) & 0.99 & 0.99 & 1.00 & 0.2950 \\
\hline \multicolumn{5}{|l|}{ TNM stages } \\
\hline T1N0M0 or T2N0M0 & ref & ref & ref & ref \\
\hline Others & 7.27 & 0.92 & 57.39 & 0.0597 \\
\hline \multicolumn{5}{|l|}{ Gleason scores } \\
\hline$\leq 7$ & ref & ref & ref & ref \\
\hline$>7$ & 0.72 & 0.14 & 3.62 & 0.6897 \\
\hline Variables for PFS & HR & Lower $95 \%$ CI & Higher $95 \%$ CI & $p$ Value \\
\hline \multicolumn{5}{|l|}{ 4-gene expression } \\
\hline Lower & ref & ref & ref & ref \\
\hline Higher & 2.32 & 1.39 & 3.95 & 0.0020 \\
\hline Age (year) & 1.00 & 0.98 & 1.04 & 0.6517 \\
\hline PSA (ng/mL) & 0.99 & 0.99 & 1.00 & 0.2380 \\
\hline \multicolumn{5}{|l|}{ TNM stages } \\
\hline T1N0M0 or T2N0M0 & ref & ref & ref & ref \\
\hline Others & 1.33 & 0.86 & 2.08 & 0.2034 \\
\hline \multicolumn{5}{|l|}{ Gleason scores } \\
\hline$\leq 7$ & ref & ref & ref & ref \\
\hline$>7$ & 2.70 & 1.61 & 4.56 & 0.0002 \\
\hline
\end{tabular}

ref: reference group. 


\subsection{Expression of the Four-Gene Panel Based on Luminal and Basal Subtypes of PC}

PAM50 is a 50-gene panel that can categorize PC into luminal A, luminal B, and basal subtypes [21]. Among them, luminal $B$ is the most aggressive and luminal $\mathrm{A}$ is the least aggressive subtype. The clinical significance of PAM50 classifier has been extensively validated in many studies and clinical trials [21,24,30-34]. Prostate Cancer Classification System (PCS) is another luminal-basal subtyping method that classifies PC into PCS1, PCS2 and PCS3 based on a 37-gene panel [23]. PCS1 is associated with the worst survival, the most resistance to antiandrogen therapy and independence of AR canonical pathway, whereas PCS2 is the least aggressive subtype [23,25]. In this study, we examined the expression of our four-gene panel based on these two well-known PC classifiers using data from an independent cohort (i.e., the DISC cohort) [23]. The analysis of gene expression based on PAM50 and PCS subtypes was conducted using the public Prostate Cancer Transcriptome Atlas (PCTA, http:/ / www.thepcta.org/; accessed date 15 September 2021) platform. The $Z$ scores of our four-gene panel were significantly associated with PAM50 (one-way ANOVA test $\mathrm{F}$ value $=133.986, p<0.001$, Figure 5a) and PCS (one-way ANOVA test $F$ value $=168.826, p<0.001$, Figure $5 b$ ) subtypes. In terms of the PAM50 system, luminal $B$ and luminal A had the highest and lowest $Z$ scores, respectively. In the PCS system, PCS1 had the highest $Z$ scores, whereas PCS2 had the lowest $Z$ scores. The expression of our four-gene panel was consistent with the aggressiveness with respect to either PAM50 or PCS classifiers.

(a) 4-gene expression based on PAM50 subtypes
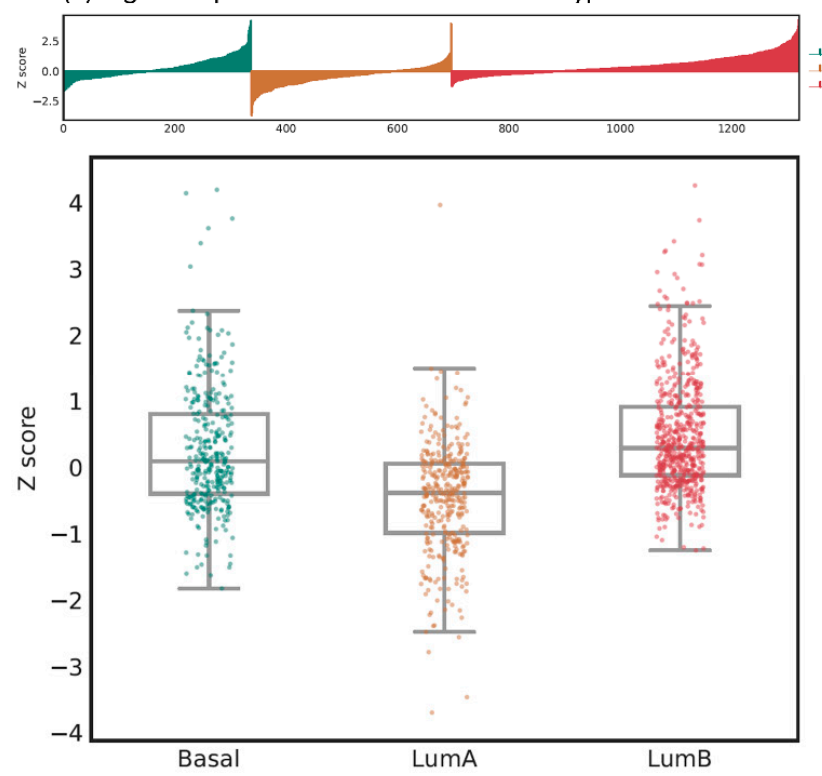

(b) 4-gene expression based on PCS subtypes
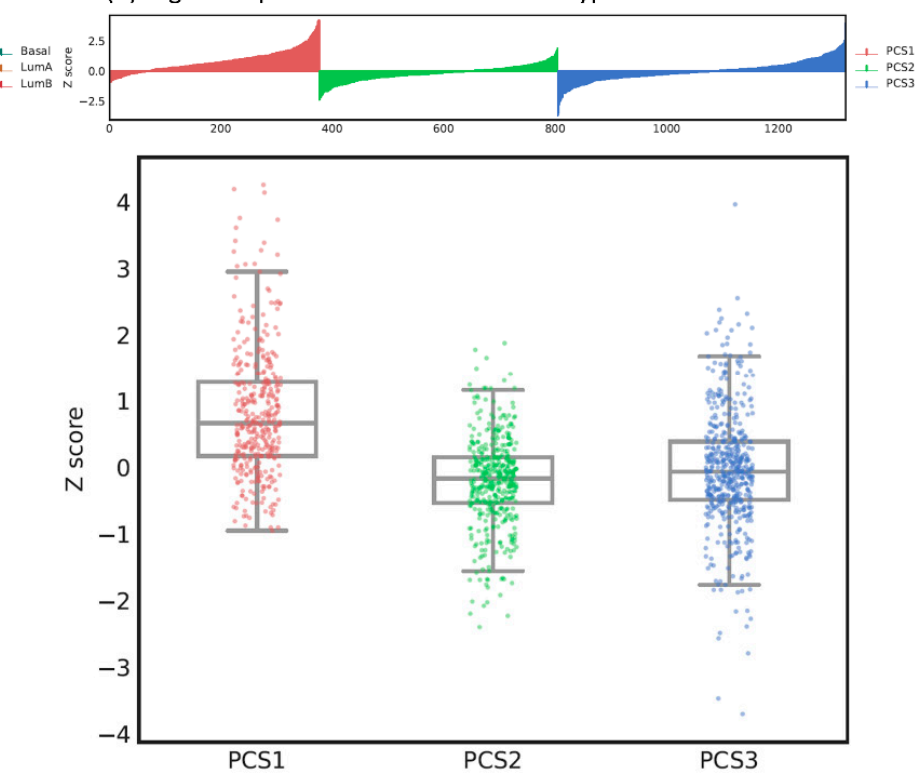

Figure 5. The expression of the 4-gene panel based on (a) PAM50 and (b) PCS subtypes.

\section{Discussion}

Aberrations of the AR signaling pathway are a hallmark of prostate carcinogenesis and thus therapies targeting AR have been the basis of PC treatments for many decades. However, it has been revealed that many other genetic changes either lead to or result in dysregulation of AR transcriptomic activity [14]. When cells with these molecular changes have defective ability of DNA repair, these permanent genomic insults will further worsen PC patients' survival and treatment response. Some researchers have also reported a positive feedback circuit between AR activity and DDR [35]. Rearrangements involving TMPRSS2, which is regulated by androgen, are shown to contribute to prostate carcinogenesis as well [36], and these structural rearrangements such as TMPRSS2-ERG translocation might result in AR-related DNA double-strand breaks [37-40]. Miller et al. found that chromosomal instability is highly indicative of metastatic potential, antiandrogen resis- 
tance and PC all-cause mortality, and is associated with the signaling pathways involving regulation of centrosomes, chromosomal segregation and assembly of mitotic spindles [41]. The functional annotation in our study also implied interactions between DDR and other biological pathways like cell cycle check points, TP53 activity, and DNA glycosylase (Supplementary Figure S1). As DDR biology is more understood, a well-developed, clinically meaningful and DDR-based biomarker could shed light into the realization for precision medicine of using DDR-targeted therapies in PC.

There have been various clinical parameters, biomarkers or commercial platforms developed for prognostication and prediction of treatment response in PC. Examples include cancer of the prostate risk assessment (CAPRA) scores [42], Decipher [43], Prolaris [44], PAM50 [21], and PCS [23]. Liquid biopsies including circulating tumor DNA (ctDNA), circulating tumor cells (CTCs) and extracellular vesicles (EVs) have also been extensively developed as a non-invasive method because they do not require tissue sampling. Of note, utilization of CTCs has been applied in PC clinical trials and even included in The Prostate Cancer Working Group 3 (PCWG3) consensus [45-47]. Moreover, the transcriptomic and protein expression of AR splice variant $7(A R-V 7)$ in CTCs was reported to be useful in selecting PC patients who could benefit from next-generation hormonal therapies [48]. EVs collected from PC patients' urine or plasma also hold the potential to be a promising biomarker [46,49]. However, very few PC biomarkers are specifically derived from DDR biology, since the first DDR-based therapy, i.e., olaparib, was just approved in May 2020 for PC; consequently, there is a clinically unmet need of DDR-based biomarkers in PC. This study provides novel insights into the transcriptomic biomarker that could indicate PC prognostication reflective of DDR biology, resulting in a four-gene panel that consists of EXO1, DNTT, NEIL3 and EME2.

EXO1 interacts with $M S H 2$ and participates in DNA mismatch repair, HRR, cell cycle checkpoints, and replication fork maintenance [50,51]. Luo et al. demonstrated that EXO1 expression is associated with the PFS and OS in PC [52]. Hua et al. identified nine RNA binding protein genes including EXO1 that have prognostic vales in PC [53]. The genetic polymorphism of EXO1 was found to elevate PC risks as well [54]. EXO1 also plays an essential role in hereditary nonpolyposis colorectal cancer and its atypical forms [55]. Recently, EXO1 was reported as being involved in non-homologous end joining and contribute to drug resistance in ovarian cancer [56]. Although the role of DNTT (also known as $T d T$ ) in PC is unclear, it has been recognized as an important marker in hematologic malignancies $[57,58]$. Merkel cell carcinoma, a rare but aggressive skin cancer, was also shown to have higher positive rate of TdT protein expression [59]. NEIL3 can secure mitotic chromosome segregation by repairing telomere damage [60], although deficiency of NEIL3 was reported to enhance resistance to chemotherapy in PC [61]. Alterations of NEIL3 are also associated with somatic mutation loads, carcinogenesis, and poor survival in many human cancers [62-64]. EME2 can promote restart of replication fork and the genetic change of EME2 and is therefore associated with DDR in malignancies [65,66]. These biological implications of our four-gene panel account for its success of prognostication in PC. It is noteworthy that EXO1 and EME2 are correlated with homologous recombination repair pathway in the functional annotation based on the Reactome database (Figure 2b). Several studies have reported that olaparib can inhibit the activity of EXO1 protein leading to inactivation of PARP enzymes [67-69], whereas there is currently no study that reports the direct interaction between PARP inhibitors and EME2.

Although the Kaplan-Meier analyses revealed statistical significance of our four-gene panel in terms of both OS and PFS, there may be clinical confounding variables that led to bias in the analyses. To overcome this issue, a multivariate Cox regression model adjusting for commonly seen clinical variables in PC was conducted and the experimental results indicated that age and baseline PSA levels were not significant variables in this model. Baseline PSA levels have been considered inappropriate as a prognostic or predictive biomarker alone [70] and must be used along with other clinical parameters for risk stratification [71]. TNM stage has been utilized in many malignancies but heterogeneity 
has been widely reported even in patients with same staging [72]. In this study, there were only three M1 PC patients (i.e., with distant metastasis), whereas most of the patients were M0 (i.e., without distant metastasis); therefore, it is rational to conclude that patients of staging other than T1N0 or T2N0 possess a trend of having greater HR of OS and PFS despite not reaching statistical significance. With respect to Gleason scores, it is reasonable that Gleason scores were correlated with the PFS but, as treatment options for advanced PC have grown expeditiously [6], the survival of patients with advanced PC has become much prolonged and the initial Gleason scores of primary tumors might not be sufficient to predict OS for PC patients. In particular, when PC patients develop distant metastasis, many other clinical characteristics are more accurate and important for prognostication such as castration sensitivity [73], metastatic site [74], number of metastatic tumors [75], and prior lines of therapy [76]. This might explain why Gleason scores in our Cox regression model did not show significance in the OS analysis. Most importantly, the expression of our four-gene panel was independently associated with both OS and PFS with statistical significance.

As the concept of luminal or basal types has been extensively accepted to describe the aggressiveness of cancer in the field of pathology, a molecular signature that can represent luminal-basal biology was also established to better classify cancers. Initially, PAM50 was developed for categorizing breast cancer into normal, luminal A, luminal B, basal and HER2 subtypes [77,78]. Since PC is also a sex-hormone-dependent malignancy, Zhao et al. successfully applied PAM50 into PC but excluded normal and HER2 subtypes [21]. They also applied PAM50 to other carcinomas including adrenocortical, pancreatic, kidney, lung cancers, etc. with clinical significance [79]. PCS is another famous luminal-basal classifier that was directly derived from multiple PC datasets [23]. Yoon et al. have demonstrated the similarity and comparability between PAM50 and PCS classifiers [22]. The expressions of our four-gene panel highly correlated with aggressiveness of both PAM50 and PCS subtypes in an independent cohort (i.e., DISC cohort). This result makes the significance of our panel more convincing.

In conclusion, the need of new biomarkers that can reflect DDR biology will be rapidly increased for not only PC but also many other malignancies because of the advent of DDRtargeted treatments. We successfully demonstrated a rigorous bioinformatic pipeline using publicly available platforms and databases including TCGA-PRAD, KEGG, DriverDBv3, and PCTA to develop a DDR-based panel that could aid with PC prognostication. The clinical and biological associations of the four-gene expression were consistent and rational between different datasets. Our study suggested that this four-gene panel consisting of EXO1, DNTT, NEIL3 and EME2 is a promising DDR-derived biomarker that should be further explored to investigate its application and effectiveness in larger clinical studies.

\section{Materials and Methods}

\subsection{Patient Clinical Information and Gene Expression Data Source}

Gene expression (RNA-seq) profiles and sample clinical profiles were curated from DriverDBv3 database and samples of TCGA-PRAD were downloaded [20]. In total, 497 patients were included in this study. The baseline characteristics of patients are shown in Supplementary Table S2.

\subsection{DNA-Repair Related Gene Selection}

Six DNA-repair-relevant KEGG pathways were selected and a total of 154 genes belonging to these pathways were curated (Supplementary Table S1). GTF2H2C_2 was not found in the TCGA-PRAD gene expression profile and was therefore discarded. In total, 153 gene expression profiles of curated genes were used for further analysis.

\subsection{Differential Expression Analysis}

Genes differentially expressed between the normal and tumor part were analyzed by DESeq2 algorithm [80]. Genes with an absolute value of $\log _{2}$-transform fold change greater 
than 1 and a $p$-value lower than 0.05 were considered statistically significant candidates, named SDE genes. Finally, 8 SDE genes were considered differentially expressed in PRAD.

\subsection{Functional Annotation}

Functional annotation of 8 SDE genes was conducted in the DriverDBv3 webserver [20]. Both the KEGG pathway database [27] and the Reactome pathway knowledgebase [28] were used to annotate genes with their associated functions, respectively.

\subsection{Additive Effect Analysis}

Additive effect of candidate genes was used to evaluate the synergic effect of combining multiple genes. Firstly, gene expression values were normalized by the z-score transformation for each gene, respectively. Secondly, the multi-gene score was calculated as the sum of normalized expression values of genes, and all possible combinations of 8 SDE genes were calculated. Thirdly, for each combination, patients were classified into two groups according to the median value of the multi-gene score, and survival analysis was conducted. Finally, the multi-gene combination with the lowest $p$-value was reported (Figure 3).

\subsection{Survival Analysis}

Univariate and multivariate Cox proportional hazards models were conducted by the "survival" library of R v4.0.1 package. Two clinical end points, OS and PFS, were analyzed. Four clinical and baseline characteristics (Supplementary Table S2) were considered as covariates in the multivariate Cox proportional hazards model: (1) patient's age in year as a continuous variable; (2) prostate-specific antigen (PSA, ng/mL) value as a continuous variable; (3) Gleason score divided by two groups ( $\leq 7 \mathrm{vs.}>7$ ) as a categorial variable; and (4) TNM stage divided by two groups (T1/T2N0M0 vs. others) as a categorial variable. A $p$-value smaller than 0.05 was considered statistically significant.

Supplementary Materials: The following are available online at https:/ / www.mdpi.com/article/10.3390/ ijms222111771/s1. Figure S1: Functional annotation of the 8 SDE genes based on Reactome, Figure S2: Kaplan-Meier plot of OS for individual genes, Table S1: Six DNA-repair relevant pathways and genes, Table S2: Patient characteristics.

Author Contributions: Conceptualization, P.-C.T., S.-P.H., W.-C.C. and C.-Y.L.; methodology, P.-C.T., W.-C.C., S.-P.H. and C.-Y.L.; software, W.-C.C. and C.-Y.L.; validation, W.-C.C., S.-P.H. and C.-Y.L.; formal analysis, P.-C.T., C.-H.L., Y.-C.C., Y.-L.L., S.-C.W., H.-C.Y., C.-P.C., D.-N.C. and W.-C.C.; investigation, C.-H.L. and W.-C.C.; resources, W.-C.C., S.-P.H. and C.-Y.L.; data curation, C.-H.L., Y.-C.C., Y.-L.L.; writing - original draft preparation, P.-C.T., T.-Y.L. and Y.-C.C.; writing-review and editing, W.-C.C., S.-P.H. and C.-Y.L.; visualization, P.-C.T., C.-H.L., T.-Y.L. and W.-C.C.; supervision, C.-Y.L.; project administration, W.-C.C., S.-P.H. and C.-Y.L.; funding acquisition, W.-C.C., S.-P.H. and C.-Y.L. All authors have read and agreed to the published version of the manuscript.

Funding: This study was supported by grants from the Ministry of Science and Technology, Taiwan, R.O.C. (grant No. MOST 108-2314-B-037-079-MY3, MOST 109-2622-E-039-004-CC2, MOST 1092628-E-039-001-MY3, MOST 109-2327-B-039-002, MOST109-2314-B-037-106-MY3 and MOST 1092320-B-037-007-MY3), Kaohsiung Medical University Chung-Ho Memorial Hospital (grant No. KMUH105-5M55), China Medical University Hospital (grant No. DMR-109-223, DMR-110-072 and DMR-110-244), and China Medical University, Taiwan, R.O.C. (grant No. CMU107-S-24, CMU108-Z02, CMU108-S-22, CMU109-MF-61 and CMU110-MF-64).

Institutional Review Board Statement: Not applicable.

Informed Consent Statement: Not applicable.

Data Availability Statement: Data will be provided on request.

Conflicts of Interest: The authors declare no conflict of interest. 


\section{References}

1. Sung, H.; Ferlay, J.; Siegel, R.L.; Laversanne, M.; Soerjomataram, I.; Jemal, A.; Bray, F. Global Cancer Statistics 2020: GLOBOCAN Estimates of Incidence and Mortality Worldwide for 36 Cancers in 185 Countries. CA Cancer J. Clin. 2021, 71, 209-249. [CrossRef] [PubMed]

2. De Bono, J.S.; Logothetis, C.J.; Molina, A.; Fizazi, K.; North, S.; Chu, L.; Chi, K.N.; Jones, R.J.; Goodman, O.B., Jr.; Saad, F.; et al. Abiraterone and increased survival in metastatic prostate cancer. N. Engl. J. Med. 2011, 364, 1995-2005. [CrossRef]

3. Scher, H.I.; Fizazi, K.; Saad, F.; Taplin, M.E.; Sternberg, C.N.; Miller, K.; de Wit, R.; Mulders, P.; Chi, K.N.; Shore, N.D.; et al. Increased survival with enzalutamide in prostate cancer after chemotherapy. N. Engl. J. Med. 2012, 367, 1187-1197. [CrossRef] [PubMed]

4. Smith, M.R.; Saad, F.; Chowdhury, S.; Oudard, S.; Hadaschik, B.A.; Graff, J.N.; Olmos, D.; Mainwaring, P.N.; Lee, J.Y.; Uemura, H.; et al. Apalutamide Treatment and Metastasis-free Survival in Prostate Cancer. N. Engl. J. Med. 2018, 378, 1408-1418. [CrossRef]

5. Fizazi, K.; Shore, N.; Tammela, T.L.; Ulys, A.; Vjaters, E.; Polyakov, S.; Jievaltas, M.; Luz, M.; Alekseev, B.; Kuss, I.; et al. Darolutamide in Nonmetastatic, Castration-Resistant Prostate Cancer. N. Engl. J. Med. 2019, 380, 1235-1246. [CrossRef]

6. Nuhn, P.; De Bono, J.S.; Fizazi, K.; Freedland, S.J.; Grilli, M.; Kantoff, P.W.; Sonpavde, G.; Sternberg, C.N.; Yegnasubramanian, S.; Antonarakis, E.S. Update on Systemic Prostate Cancer Therapies: Management of Metastatic Castration-resistant Prostate Cancer in the Era of Precision Oncology. Eur. Urol. 2018, 75, 88-99. [CrossRef]

7. Hussain, M.; Mateo, J.; Fizazi, K.; Saad, F.; Shore, N.; Sandhu, S.; Chi, K.N.; Sartor, O.; Agarwal, N.; Olmos, D.; et al. Survival with Olaparib in Metastatic Castration-Resistant Prostate Cancer. N. Engl. J. Med. 2020, 383, 2345-2357. [CrossRef]

8. De Bono, J.; Mateo, J.; Fizazi, K.; Saad, F.; Shore, N.; Sandhu, S.; Chi, K.N.; Sartor, O.; Agarwal, N.; Olmos, D.; et al. Olaparib for Metastatic Castration-Resistant Prostate Cancer. N. Engl. J. Med. 2020, 382, 2091-2102. [CrossRef] [PubMed]

9. Cancer Genome Atlas Research Network. The Molecular Taxonomy of Primary Prostate Cancer. Cell 2015, 163, 1011-1025. [CrossRef]

10. Lang, S.H.; Swift, S.L.; White, H.; Misso, K.; Kleijnen, J.; Quek, R.G. A systematic review of the prevalence of DNA damage response gene mutations in prostate cancer. Int. J. Oncol. 2019, 55, 597-616. [CrossRef]

11. Robinson, D.; Van Allen, E.M.; Wu, Y.M.; Schultz, N.; Lonigro, R.J.; Mosquera, J.M.; Montgomery, B.; Taplin, M.E.; Pritchard, C.C.; Attard, G.; et al. Integrative clinical genomics of advanced prostate cancer. Cell 2015, 161, 1215-1228. [CrossRef]

12. Jin, M.H.; Oh, D.Y. ATM in DNA repair in cancer. Pharmacol. Ther. 2019, 203, 107391. [CrossRef]

13. Li, X.; Heyer, W.D. Homologous recombination in DNA repair and DNA damage tolerance. Cell Res. 2008, 18, 99-113. [CrossRef] [PubMed]

14. Mateo, J.; Boysen, G.; Barbieri, C.E.; Bryant, H.E.; Castro, E.; Nelson, P.S.; Olmos, D.; Pritchard, C.C.; Rubin, M.A.; de Bono, J.S. DNA Repair in Prostate Cancer: Biology and Clinical Implications. Eur. Urol. 2017, 71, 417-425. [CrossRef]

15. Bryant, H.E.; Schultz, N.; Thomas, H.D.; Parker, K.M.; Flower, D.; Lopez, E.; Kyle, S.; Meuth, M.; Curtin, N.J.; Helleday, T. Specific killing of BRCA2-deficient tumours with inhibitors of poly(ADP-ribose) polymerase. Nature 2005, 434, 913-917. [CrossRef] [PubMed]

16. Mateo, J.; Carreira, S.; Sandhu, S.; Miranda, S.; Mossop, H.; Perez-Lopez, R.; Nava Rodrigues, D.; Robinson, D.; Omlin, A.; Tunariu, N.; et al. DNA-Repair Defects and Olaparib in Metastatic Prostate Cancer. N. Engl. J. Med. 2015, 373, 1697-1708. [CrossRef]

17. Chatterjee, N.; Walker, G.C. Mechanisms of DNA damage, repair, and mutagenesis. Env. Mol. Mutagen 2017, 58, 235-263. [CrossRef]

18. Gong, J.; Posadas, E.; Bhowmick, N.; Kim, H.; Daskivich, T.; Gupta, A.; Sandler, H.; Kamrava, M.; Zumsteg, Z.; Freedland, S.; et al. Integrating PARP Inhibitors Into Advanced Prostate Cancer Therapeutics. Oncology 2021, 35, 119-125. [CrossRef] [PubMed]

19. Walden, H.; Deans, A.J. The Fanconi anemia DNA repair pathway: Structural and functional insights into a complex disorder. Annu. Rev. Biophys. 2014, 43, 257-278. [CrossRef]

20. Liu, S.H.; Shen, P.C.; Chen, C.Y.; Hsu, A.N.; Cho, Y.C.; Lai, Y.L.; Chen, F.H.; Li, C.Y.; Wang, S.C.; Chen, M.; et al. DriverDBv3: A multi-omics database for cancer driver gene research. Nucleic Acids Res. 2020, 48, 863-870. [CrossRef]

21. Zhao, S.G.; Chang, S.L.; Erho, N.; Yu, M.; Lehrer, J.; Alshalalfa, M.; Speers, C.; Cooperberg, M.R.; Kim, W.; Ryan, C.J. Associations of Luminal and Basal Subtyping of Prostate Cancer With Prognosis and Response to Androgen Deprivation Therapy. JAMA Oncol. 2017, 3, 1663-1672. [CrossRef]

22. Yoon, J.; Kim, M.; Posadas, E.M.; Freedland, S.J.; Liu, Y.; Davicioni, E.; Den, R.B.; Trock, B.J.; Karnes, R.J.; Klein, E.A. A comparative study of PCS and PAM50 prostate cancer classification schemes. Prostate Cancer Prostatic Dis. 2021, 24, 733-742. [CrossRef] [PubMed]

23. You, S.; Knudsen, B.S.; Erho, N.; Alshalalfa, M.; Takhar, M.; Al-Deen Ashab, H.; Davicioni, E.; Karnes, R.J.; Klein, E.A.; Den, R.B. Integrated Classification of Prostate Cancer Reveals a Novel Luminal Subtype with Poor Outcome. Cancer Res. 2016, 76, $4948-4958$. [CrossRef] [PubMed]

24. Feng, F.Y.; Thomas, S.; Saad, F.; Gormley, M.; Yu, M.K.; Ricci, D.S.; Rooney, B.; Brookman-May, S.; McCarthy, S.; Olmos, D.; et al. Association of Molecular Subtypes With Differential Outcome to Apalutamide Treatment in Nonmetastatic Castration-Resistant Prostate Cancer. JAMA Oncol. 2021, 7, 1005-1014. [CrossRef] [PubMed] 
25. Jan, Y.J.; Yoon, J.; Chen, J.F.; Teng, P.C.; Yao, N.; Cheng, S.; Lozano, A.; Chu, G.C.Y.; Chung, H.; Lu, Y.T.; et al. A Circulating Tumor Cell-RNA Assay for Assessment of Androgen Receptor Signaling Inhibitor Sensitivity in Metastatic Castration-Resistant Prostate Cancer. Theranostics 2019, 9, 2812-2826. [CrossRef]

26. Ogata, H.; Goto, S.; Fujibuchi, W.; Kanehisa, M. Computation with the KEGG pathway database. Biosystems 1998, 47, 119-128. [CrossRef]

27. Kanehisa, M.; Sato, Y.; Kawashima, M.; Furumichi, M.; Tanabe, M. KEGG as a reference resource for gene and protein annotation. Nucleic Acids Res. 2016, 44, 457-462. [CrossRef] [PubMed]

28. Jassal, B.; Matthews, L.; Viteri, G.; Gong, C.; Lorente, P.; Fabregat, A.; Sidiropoulos, K.; Cook, J.; Gillespie, M.; Haw, R.; et al. The reactome pathway knowledgebase. Nucleic Acids Res. 2020, 48, 498-503. [CrossRef] [PubMed]

29. Christensen, E. Multivariate survival analysis using Cox's regression model. Hepatology 1987, 7, 1346-1358. [CrossRef] [PubMed]

30. Teng, P.-C.; Jan, Y.J.; Kim, M.; Chen, J.-F.; Yoon, J.; Wang, J.J.; Chen, P.-J.; Yao, N.; Lee, Y.-T.; Lozano, A.; et al. Development of a circulating tumor cell-based RNA classifier for patients with castration-resistant prostate cancer: CTC-PCS/PAM50. J. Clin. Oncol. 2020, 38, e17509. [CrossRef]

31. Hamid, A.; Wang, X.V.; Chen, Y.-H.; Feng, F.Y.; Den, R.B.; Attard, G.; Allen, E.M.V.; Huang, H.-C.; Karns, A.; Dittamore, R.; et al. Luminal B subtype as a predictive biomarker of docetaxel benefit for newly diagnosed metastatic hormone sensitive prostate cancer (mHSPC): A correlative study of E3805 CHAARTED. J. Clin. Oncol. 2020, 38, 162. [CrossRef]

32. Feng, F.Y.; Thomas, S.; Aguilar-Bonavides, C.; Gormley, M.; Agarwal, N.; Attard, G.; Wyatt, A.W.; Davicioni, E.; Ricci, D.S.; Lopez-Gitlitz, A.; et al. Molecular determinants of outcome for metastatic castration-sensitive prostate cancer (mCSPC) with addition of apalutamide (APA) or placebo (PBO) to androgen deprivation therapy (ADT) in TITAN. J. Clin. Oncol. 2020, $38,5535$. [CrossRef]

33. Kim, W.; Small, E.J.; Aggarwal, R.R.; Den, R.B.; Lehrer, J.; Zhang, L.; Youngren, J.; Goldstein, T.C.; Alumkal, J.J.; Gleave, M.; et al. Luminal and basal subtyping of metastatic castration-resistant prostate cancer (mCRPC) and its clinical implications. J. Clin. Oncol. 2018, 36, 197. [CrossRef]

34. Cooperberg, M.R.; Erho, N.; Chan, J.M.; Feng, F.Y.; Fishbane, N.; Zhao, S.G.; Simko, J.P.; Cowan, J.E.; Lehrer, J.; Alshalalfa, M.; et al. The Diverse Genomic Landscape of Clinically Low-risk Prostate Cancer. Eur. Urol. 2018, 74, 444-452. [CrossRef]

35. Goodwin, J.F.; Schiewer, M.J.; Dean, J.L.; Schrecengost, R.S.; de Leeuw, R.; Han, S.; Ma, T.; Den, R.B.; Dicker, A.P.; Feng, F.Y. A hormone-DNA repair circuit governs the response to genotoxic insult. Cancer Discov. 2013, 3, 1254-1271. [CrossRef]

36. Mehra, R.; Tomlins, S.A.; Shen, R.; Nadeem, O.; Wang, L.; Wei, J.T.; Pienta, K.J.; Ghosh, D.; Rubin, M.A.; Chinnaiyan, A.M.; et al. Comprehensive assessment of TMPRSS2 and ETS family gene aberrations in clinically localized prostate cancer. Mod. Pathol. 2007, 20, 538-544. [CrossRef] [PubMed]

37. Wu, C.; Wyatt, A.W.; McPherson, A.; Lin, D.; McConeghy, B.J.; Mo, F.; Shukin, R.; Lapuk, A.V.; Jones, S.J.; Zhao, Y.; et al. Poly-gene fusion transcripts and chromothripsis in prostate cancer. Genes Chromosomes Cancer 2012, 51, 1144-1153. [CrossRef]

38. Mani, R.S.; Tomlins, S.A.; Callahan, K.; Ghosh, A.; Nyati, M.K.; Varambally, S.; Palanisamy, N.; Chinnaiyan, A.M. Induced chromosomal proximity and gene fusions in prostate cancer. Science 2009, 326, 1230. [CrossRef] [PubMed]

39. Ju, B.G.; Lunyak, V.V.; Perissi, V.; Garcia-Bassets, I.; Rose, D.W.; Glass, C.K.; Rosenfeld, M.G. A topoisomerase Ilbeta-mediated dsDNA break required for regulated transcription. Science 2006, 312, 1798-1802. [CrossRef] [PubMed]

40. Tomlins, S.A.; Rhodes, D.R.; Perner, S.; Dhanasekaran, S.M.; Mehra, R.; Sun, X.W.; Varambally, S.; Cao, X.; Tchinda, J.; Kuefer, R.; et al. Recurrent fusion of TMPRSS2 and ETS transcription factor genes in prostate cancer. Science 2005, 310, 644-648. [CrossRef]

41. Miller, E.T.; You, S.; Cadaneanu, R.M.; Kim, M.; Yoon, J.; Liu, S.T.; Li, X.; Kwan, L.; Hodge, J.; Quist, M.J.; et al. Chromosomal instability in untreated primary prostate cancer as an indicator of metastatic potential. BMC Cancer 2020, 20, 398. [CrossRef]

42. Cooperberg, M.R.; Broering, J.M.; Carroll, P.R. Time trends and local variation in primary treatment of localized prostate cancer. J. Clin. Oncol. 2010, 28, 1117-1123. [CrossRef]

43. Erho, N.; Crisan, A.; Vergara, I.A.; Mitra, A.P.; Ghadessi, M.; Buerki, C.; Bergstralh, E.J.; Kollmeyer, T.; Fink, S.; Haddad, Z.; et al. Discovery and validation of a prostate cancer genomic classifier that predicts early metastasis following radical prostatectomy. PLoS ONE 2013, 8, e66855. [CrossRef]

44. Cuzick, J.; Swanson, G.P.; Fisher, G.; Brothman, A.R.; Berney, D.M.; Reid, J.E.; Mesher, D.; Speights, V.O.; Stankiewicz, E.; Foster, C.S.; et al. Prognostic value of an RNA expression signature derived from cell cycle proliferation genes in patients with prostate cancer: A retrospective study. Lancet Oncol 2011, 12, 245-255. [CrossRef]

45. Casanova-Salas, I.; Athie, A.; Boutros, P.C.; Del Re, M.; Miyamoto, D.T.; Pienta, K.J.; Posadas, E.M.; Sowalsky, A.G.; Stenzl, A.; Wyatt, A.W.; et al. Quantitative and Qualitative Analysis of Blood-based Liquid Biopsies to Inform Clinical Decision-making in Prostate Cancer. Eur. Urol. 2021, 79, 762-771. [CrossRef] [PubMed]

46. Duijvesz, D.; Versluis, C.Y.; van der Fels, C.A.; Vredenbregt-van den Berg, M.S.; Leivo, J.; Peltola, M.T.; Bangma, C.H.; Pettersson, K.S.; Jenster, G. Immuno-based detection of extracellular vesicles in urine as diagnostic marker for prostate cancer. Int. J. Cancer 2015, 137, 2869-2878. [CrossRef]

47. Scher, H.I.; Morris, M.J.; Stadler, W.M.; Higano, C.; Basch, E.; Fizazi, K.; Antonarakis, E.S.; Beer, T.M.; Carducci, M.A.; Chi, K.N.; et al. Trial Design and Objectives for Castration-Resistant Prostate Cancer: Updated Recommendations From the Prostate Cancer Clinical Trials Working Group 3. J. Clin. Oncol. 2016, 34, 1402-1418. [CrossRef] 
48. Armstrong, A.J.; Halabi, S.; Luo, J.; Nanus, D.M.; Giannakakou, P.; Szmulewitz, R.Z.; Danila, D.C.; Healy, P.; Anand, M.; Rothwell, C.J.; et al. Prospective Multicenter Validation of Androgen Receptor Splice Variant 7 and Hormone Therapy Resistance in High-Risk Castration-Resistant Prostate Cancer: The PROPHECY Study. J. Clin. Oncol. 2019, 37, 1120-1129. [CrossRef] [PubMed]

49. Del Re, M.; Biasco, E.; Crucitta, S.; Derosa, L.; Rofi, E.; Orlandini, C.; Miccoli, M.; Galli, L.; Falcone, A.; Jenster, G.W.; et al. The Detection of Androgen Receptor Splice Variant 7 in Plasma-derived Exosomal RNA Strongly Predicts Resistance to Hormonal Therapy in Metastatic Prostate Cancer Patients. Eur. Urol. 2017, 71, 680-687. [CrossRef] [PubMed]

50. Bolderson, E.; Tomimatsu, N.; Richard, D.J.; Boucher, D.; Kumar, R.; Pandita, T.K.; Burma, S.; Khanna, K.K. Phosphorylation of Exo1 modulates homologous recombination repair of DNA double-strand breaks. Nucleic Acids Res. 2010, 38, $1821-1831$. [CrossRef]

51. Keijzers, G.; Bakula, D.; Petr, M.A.; Madsen, N.G.K.; Teklu, A.; Mkrtchyan, G.; Osborne, B.; Scheibye-Knudsen, M. Human Exonuclease 1 (EXO1) Regulatory Functions in DNA Replication with Putative Roles in Cancer. Int. J. Mol. Sci. 2018, 20, 74. [CrossRef]

52. Luo, F.; Wang, Y.Z.; Lin, D.; Li, J.; Yang, K. Exonuclease 1 expression is associated with clinical progression, metastasis, and survival prognosis of prostate cancer. J. Cell Biochem. 2019, 120, 11383-11389. [CrossRef] [PubMed]

53. Hua, X.; Ge, S.; Chen, J.; Zhang, L.; Tai, S.; Liang, C. Effects of RNA Binding Proteins on the Prognosis and Malignant Progression in Prostate Cancer. Front. Genet. 2020, 11, 591667. [CrossRef] [PubMed]

54. Imtiaz, H.; Afroz, S.; Hossain, M.A.; Bellah, S.F.; Rahman, M.M.; Kadir, M.S.; Sultana, R.; Mazid, M.A.; Rahman, M.M. Genetic polymorphisms in CDH1 and Exo1 genes elevate the prostate cancer risk in Bangladeshi population. Tumour Biol. 2019, 41, 1010428319830837. [CrossRef]

55. Wu, Y.; Berends, M.J.; Post, J.G.; Mensink, R.G.; Verlind, E.; Van Der Sluis, T.; Kempinga, C.; Sijmons, R.H.; van der Zee, A.G.; Hollema, H.; et al. Germline mutations of EXO1 gene in patients with hereditary nonpolyposis colorectal cancer (HNPCC) and atypical HNPCC forms. Gastroenterology 2001, 120, 1580-1587. [CrossRef]

56. He, D.; Li, T.; Sheng, M.; Yang, B. Exonuclease 1 (Exo1) Participates in Mammalian Non-Homologous End Joining and Contributes to Drug Resistance in Ovarian Cancer. Med. Sci. Monit. 2020, 26, e918751. [CrossRef]

57. Venditti, A.; Del Poeta, G.; Buccisano, F.; Tamburini, A.; Cox-Froncillo, M.C.; Aronica, G.; Bruno, A.; Del Moro, B.; Epiceno, A.M.; Battaglia, A.; et al. Prognostic relevance of the expression of Tdt and CD7 in 335 cases of acute myeloid leukemia. Leukemia 1998, 12, 1056-1063. [CrossRef] [PubMed]

58. Ok, C.Y.; Medeiros, L.J.; Thakral, B.; Tang, G.; Jain, N.; Jabbour, E.; Pierce, S.A.; Konoplev, S. High-grade B-cell lymphomas with TdT expression: A diagnostic and classification dilemma. Mod. Pathol. 2019, 32, 48-58. [CrossRef]

59. Sidiropoulos, M.; Hanna, W.; Raphael, S.J.; Ghorab, Z. Expression of TdT in Merkel cell carcinoma and small cell lung carcinoma. Am. J. Clin. Pathol. 2011, 135, 831-838. [CrossRef]

60. Zhou, J.; Chan, J.; Lambele, M.; Yusufzai, T.; Stumpff, J.; Opresko, P.L.; Thali, M.; Wallace, S.S. NEIL3 Repairs Telomere Damage during S Phase to Secure Chromosome Segregation at Mitosis. Cell Rep. 2017, 20, 2044-2056. [CrossRef]

61. Wang, Y.; Xu, L.; Shi, S.; Wu, S.; Meng, R.; Chen, H.; Jiang, Z. Deficiency of NEIL3 Enhances the Chemotherapy Resistance of Prostate Cancer. Int. J. Mol. Sci. 2021, 22, 4098. [CrossRef]

62. Tran, O.T.; Tadesse, S.; Chu, C.; Kidane, D. Overexpression of NEIL3 associated with altered genome and poor survival in selected types of human cancer. Tumor Biol. 2020, 42, 1010428320918404. [CrossRef] [PubMed]

63. Shinmura, K.; Kato, H.; Kawanishi, Y.; Igarashi, H.; Goto, M.; Tao, H.; Inoue, Y.; Nakamura, S.; Misawa, K.; Mineta, H.; et al. Abnormal Expressions of DNA Glycosylase Genes NEIL1, NEIL2, and NEIL3 Are Associated with Somatic Mutation Loads in Human Cancer. Oxid. Med. Cell Longev. 2016, 2016, 1546392. [CrossRef] [PubMed]

64. Wang, W.; Yin, Q.; Guo, S.; Wang, J. NEIL3 contributes toward the carcinogenesis of liver cancer and regulates PI3K/Akt/mTOR signaling. Exp. Ther. Med. 2021, 22, 1053. [CrossRef] [PubMed]

65. Techer, H.; Koundrioukoff, S.; Carignon, S.; Wilhelm, T.; Millot, G.A.; Lopez, B.S.; Brison, O.; Debatisse, M. Signaling from Mus81-Eme2-Dependent DNA Damage Elicited by Chk1 Deficiency Modulates Replication Fork Speed and Origin Usage. Cell Rep. 2016, 14, 1114-1127. [CrossRef]

66. Pepe, A.; West, S.C. MUS81-EME2 promotes replication fork restart. Cell Rep. 2014, 7, 1048-1055. [CrossRef] [PubMed]

67. Li, Y.; Wang, Y.; Zhang, W.; Wang, X.; Chen, L.; Wang, S. BKM120 sensitizes BRCA-proficient triple negative breast cancer cells to olaparib through regulating FOXM1 and Exo1 expression. Sci. Rep. 2021, 11, 4774. [CrossRef] [PubMed]

68. Zhang, F.; Shi, J.; Chen, S.H.; Bian, C.; Yu, X. The PIN domain of EXO1 recognizes poly(ADP-ribose) in DNA damage response. Nucleic Acids Res. 2015, 43, 10782-10794. [CrossRef]

69. Cheruiyot, A.; Paudyal, S.C.; Kim, I.K.; Sparks, M.; Ellenberger, T.; Piwnica-Worms, H.; You, Z. Poly(ADP-ribose)-binding promotes Exo1 damage recruitment and suppresses its nuclease activities. DNA Repair 2015, 35, 106-115. [CrossRef] [PubMed]

70. Prensner, J.R.; Rubin, M.A.; Wei, J.T.; Chinnaiyan, A.M. Beyond PSA: The next generation of prostate cancer biomarkers. Sci. Transl. Med. 2012, 4, 127rv3. [CrossRef]

71. Mohler, J.L.; Antonarakis, E.S.; Armstrong, A.J.; D'Amico, A.V.; Davis, B.J.; Dorff, T.; Eastham, J.A.; Enke, C.A.; Farrington, T.A.; Higano, C.S.; et al. Prostate Cancer, Version 2.2019, NCCN Clinical Practice Guidelines in Oncology. J. Natl. Compr. Cancer Netw. 2019, 17, 479-505. [CrossRef]

72. Meacham, C.E.; Morrison, S.J. Tumour heterogeneity and cancer cell plasticity. Nature 2013, 501, 328-337. [CrossRef] [PubMed] 
73. Scher, H.I.; Solo, K.; Valant, J.; Todd, M.B.; Mehra, M. Prevalence of Prostate Cancer Clinical States and Mortality in the United States: Estimates Using a Dynamic Progression Model. PLoS ONE 2015, 10, e0139440. [CrossRef]

74. Halabi, S.; Kelly, W.K.; Ma, H.; Zhou, H.; Solomon, N.C.; Fizazi, K.; Tangen, C.M.; Rosenthal, M.; Petrylak, D.P.; Hussain, M.; et al. Meta-Analysis Evaluating the Impact of Site of Metastasis on Overall Survival in Men With Castration-Resistant Prostate Cancer. J. Clin. Oncol. 2016, 34, 1652-1659. [CrossRef]

75. Phillips, R.; Shi, W.Y.; Deek, M.; Radwan, N.; Lim, S.J.; Antonarakis, E.S.; Rowe, S.P.; Ross, A.E.; Gorin, M.A.; Deville, C.; et al. Outcomes of Observation vs Stereotactic Ablative Radiation for Oligometastatic Prostate Cancer: The ORIOLE Phase 2 Randomized Clinical Trial. JAMA Oncol. 2020, 6, 650-659. [CrossRef]

76. Scher, H.I.; Lu, D.; Schreiber, N.A.; Louw, J.; Graf, R.P.; Vargas, H.A.; Johnson, A.; Jendrisak, A.; Bambury, R.; Danila, D.; et al. Association of AR-V7 on Circulating Tumor Cells as a Treatment-Specific Biomarker With Outcomes and Survival in Castration-Resistant Prostate Cancer. JAMA Oncol. 2016, 2, 1441-1449. [CrossRef]

77. Cancer Genome Atlas Network. Comprehensive molecular portraits of human breast tumours. Nature 2012, 490, 61-70. [CrossRef]

78. Perou, C.M.; Sorlie, T.; Eisen, M.B.; van de Rijn, M.; Jeffrey, S.S.; Rees, C.A.; Pollack, J.R.; Ross, D.T.; Johnsen, H.; Akslen, L.A.; et al. Molecular portraits of human breast tumours. Nature 2000, 406, 747-752. [CrossRef]

79. Zhao, S.G.; Chen, W.S.; Das, R.; Chang, S.L.; Tomlins, S.A.; Chou, J.; Quigley, D.A.; Dang, H.X.; Barnard, T.J.; Mahal, B.A.; et al. Clinical and Genomic Implications of Luminal and Basal Subtypes Across Carcinomas. Clin. Cancer Res. 2019, 25, $2450-2457$. [CrossRef] [PubMed]

80. Love, M.I.; Huber, W.; Anders, S. Moderated estimation of fold change and dispersion for RNA-seq data with DESeq2. Genome Biol. 2014, 15, 550. [CrossRef] 